\title{
Effects of the static magnetic field on brain, lungs, liver, pancreas and blood electrolytes of rats
}

\author{
Mohammed Farahna ${ }^{a}$, Mohammed A. Ali Omer ${ }^{\mathrm{a}, \mathrm{b}}$, Mohamed E. M. Garalnabi ${ }^{\mathrm{b}}$, A. A. Al-Ganim ${ }^{\mathrm{a}}$, Saida Abdelkareem ${ }^{\mathrm{b}}$, \\ Yahia M. Bushara ${ }^{a, c}$
}

${ }^{a}$ Radiologic Technology Department and Department of Basic Health Sciences, College of Applied Medical Science, Qassim University, Buraidah, KSA

${ }^{b}$ College of Medical, Radiologic Science, Sudan University of Science and Technology, Khartoum, Sudan

${ }^{c}$ Department of Anatomy, Faculty of Medicine and Health Sciences, Al-Neelain University, Khartoum, Sudan

\section{ARTICLE INFO}

* Correspondence to:

Mohammed Farahna

Radiologic Technology Department and

Department of Basic Health Sciences,

College of Applied Medical Science,

Qassim University, Buraidah-KSA

e-mail: farahnamohammed@hotmail.com

\section{ABSTRACT}

The effects of static magnetic field of 1.5 Tesla during exposure time of 0-3 hours have been characterized among four groups (E0, E1, E2 and E3) of Rat's tissues (brain, lungs, liver and pancreas) and blood electrolytes $\left(\mathrm{Na}^{+}, \mathrm{K}^{+}\right.$and $\left.\mathrm{Ca}^{+2}\right)$. Before the exposure, the average levels for electrolytes were $116.81 \pm 3.67,5.16 \pm 0.28 \mathrm{mmol} / 1$ and $10.23 \pm 0.07 \mathrm{mg} /$ $\mathrm{dl}$ respectively. Then a significant $(\mathrm{R} 2=98, \mathrm{P}=0.05)$ reduction in $\mathrm{Na}^{+}, \mathrm{Ca}^{+2}$ have been noticed following the exposure time in a linear correlation observed and the reduction was $31.55 \%$ and $15.59 \%$ respectively, while the $\mathrm{K}^{+}$increased following the exposure time in a linear form and the reduction percent at three hours of exposure was $47.76 \%$. While the observed effects in tissues were edema (vacuolations) and degeneration in brain tissue. Alveolar congestion, emphysema and hemorrhage have seen in the lungs tissue. Atrophied hepatocytes and necrosis seen in the pancreas.

J.Exp.Clin. Med., 2014; 31:124

\section{Keywords:}

Blood electrolytes

Brain

Liver

Lungs

Pancreas

Static magnetic field 